\title{
O Mário que existe em nós
}

\section{The Mário in us}

Mário Eduardo Costa Pereira dedica sua $A$ erótica do sono à a sua avó Regina e isso já diz muito de tudo o que esse livro nos reserva. Assim, preparem-se para um encontro. É a isso que o autor nos convida. Paradoxalmente, ele nos desperta para nos reconciliarmos com nosso sono, o que em sua concepção significa nos reconciliarmos com nós mesmos, em tempos de ligação geral.

Nosso autor, valendo-se de uma linguagem literária, recorda os acalantos que embalavam seu sono na infância, tecendo um texto que instiga nossa própria memória. É dessa maneira autoral e implicada que seu texto tem a densidade da experiência vivida, ao mesmo tempo que revela uma erudição admirável, e o rigor de alguém que pensa a ciência a serviço do humano e não o contrário. É assim que suas várias inserções: psicanalista, psiquiatra, professor, escritor, encontram-se delicadamente articuladas nesse volume.

*1 Universidade Federal do Estado do Rio de Janeiro - Unirio (Rio de Janeiro, RJ, Brasil). 
Se o sono é um imperativo biológico que responde a exigências fisiológicas de importante caráter reparador de várias funções psíquicas, como a memória por exemplo, marcando a presença da natureza em nós, o artifício de nossa condição humana subverte nossos condicionantes biológicos. Costa Pereira nos adverte que "A natureza do sono é moldada no colo do Outro" (p. 20). Eis, portanto, a razão pela qual abordar o sono e suas perturbações (insônia, sono inquieto e outras) implica considerar as contingências de sua consistência amorosa, erótica, introduzida pelas relações estabelecidas com nossos primeiros cuidadores.

Bem para além de dever servir a essa função fisiológica do repouso, o sono comporta uma satisfação na qual "a mente descansa do ego" vigilante, para que se possa desfrutar do alívio das tantas exigências que pesam sobre nós e nos seja permitida uma dimensão de gozo, de entrega, donde se espera que advenha o prazer de dormir. Tal recolhimento sobre si mesmo onde se desliga das exigências egoicas é tão importante que justifica até mesmo a produção de sonhos cuja função, freudianamente falando, é de ser "guardião do sono". Assim sonhamos para não acordar.

Mas, paradoxalmente, essa entrega passiva acorda, com o trabalho do sonho, o reencontro de desejos recalcados, a elaboração de traumas vividos, ou expectados, a reorganização da memória, dos conflitos, e toda uma gama dos restos do dia que ficou em suspensão, demandando elaboração. É nesse "gozo de ser próprio ao sono" que, através do sonho, curiosamente, o sujeito tem seu encontro marcado com a hora da verdade, despido de todas as máscaras e próteses que sustentam seu ego vigilante, mas não ausente das marcas inscritas pelo Outro em nós.

Porém, como operar com isso num mundo que condena o sono, despreza o sonho e exige que estejamos permanentemente antenados, conectados com um produtivismo no qual o espaço do sujeito fica reduzido ao desempenho de seu ego? Como conciliar com o sono se temos que operar o atendimento a demandas ininterruptas, num mundo competitivo no qual "não se pode dormir no ponto"?

Nosso autor chama a atenção para essa dupla inserção da questão do sono: por um lado, atende exigências singulares, tanto do ponto de vista biológico quanto subjetivo, e, por outro, responde a injunções sociais relativas a cada época, sobretudo desde que foi possível a iluminação da noite, com o advento e popularização da luz elétrica e tudo que adveio disso em termos da mudança das relações com o trabalho.

A erótica do sono nos faz também revisitar algumas pérolas das obras de Shakespeare que é aqui tomado como o grande poeta que antecipa aquilo 
que o cientista ainda não tinha vislumbrado. Nesse caso, trata-se da relação do sono com o sonho e com a morte, mostrando de que maneira o artista precede o psicanalista (Lacan, 1965/2003), tal como Freud (1907/1996) também já o havia mencionado ao analisar a Gradiva, uma obra do escritor Wilhelm Jensen.

Certamente são fartas as referências mitológicas, literárias e mesmo clínicas, da relação do sono com a morte. Não à toa, na mitologia, Dioniso, por ser o deus do vinho e o vinho levar ao sono, é também considerado o profeta da morte. Costa Pereira explora, especialmente em Hamlet e Macbeth, toda a densidade da experiência do dormir e suas perturbações, como a insônia, ou o sono inquieto, para sublinhar a fragilidade a qual se é exposto nessa deposição de si mesmo, que confunde o sono com a morte. Sobretudo quando entregar-se ao desamparo e ao indeterminado, significa adentrar uma terra desconhecida acossada pelos malfeitos da vigília, como se passa com Macbeth, por exemplo, cuja experiência do sono é confiscada ou "assassinada", pelos ruídos da turbulência da vociferação do Outro nele mesmo.

Muito longe de tratar o sono e seus impasses como um problema técnico de saúde, tal como a tendência organicista no campo médico tem feito, aqui 794 o estatuto metapsicológico do sono é resgatado na perspectiva freudiana, e a abordagem psicopatológica da insônia passa a ser uma via de questionamento do sujeito. A psicopatologia é tratada não como um tipo de degeneração, mas no rigor do sentido etimológico do termo: busca de sentido (logia) do que causa espanto (pathos) à alma (psique). Interrogando o sujeito sobre: $\mathrm{O}$ que será mesmo que te desperta, no momento de repousar? No momento de pousar sobre si mesmo, se abandonando a um gozo corporal, esvaziado de toda excitação, numa "restauração regressiva do narcisismo primitivo"? (p. 91)

Nessa modalidade narcísica relativa ao sono, o Eu é destituído de suas próteses, máscaras, maquiagens, e é colocado em suspensão, pronto a uma fruição creditada à própria experiência intra-uterina. Se exigências pulsionais da vida de vigília persistirem, o trabalho do sonho deverá cumprir a função de realizá-las de algum modo, de forma a levar a cabo o desejo mais fundamental que seria o desejo de dormir. Porém, o Eu também pode desistir do desejo de dormir por temer que seus sonhos lhe apresentem pulsões inconscientes inconciliáveis, motivando a clivagem que leva à insônia.

São muitas as questões instigantes tocadas de maneira clara e concisa nesse volume, que nos instigam a dialogar com o autor. Como, por exemplo, o que seria essa fruição do sono creditada a esse narcisismo aqui também aludido como absoluto? Qual o gozo aí implicado? Avançando para a 
suposição lacaniana de que haveria duas modalidades de gozo, um fálico, centrado na afirmação de si mesmo e um Outro, feminino, dessubjetivado, aludido como gozo Outro, será que a modalidade de fruição quase beatífica presente no sono, "gozo do ser" não poderia ser relacionada a uma das manifestações desse gozo Outro como entrega consentida? E será que poderíamos fazer uma distinção deste e do gozo do Outro, sendo este último, sim, fonte de angústia, combustível para o terror noturno no qual o sujeito, entregue como carne, submete-se ao gozo imperativo do Outro, sem mediações?

Outro ponto instigante desse trabalho refere-se ao reconhecimento do que aqui é chamado de "marcas da Mãe Preta no sono à brasileira" (p. 149), lembrando que os processos de subjetivação do povo brasileiro não podem desconhecer tais marcas que vão desde a ama de leite, que funcionava como um duplo da mãe branca, e que foi instituidora do cafuné na nossa corporeidade, até as babás contemporâneas. Essa carícia terna nos cabelos, como um chamado a paz que leva ao adormecimento, acompanhado frequentemente pelo acalanto, é como um canto de sereia que traz um tipo de encantação, mas longe de levar para a obscuridade da morte, funciona como proteção asseguradora frente ao escuro da noite e os terrores que ele poderia suscitar. E imprime à nossa erotização características bem particulares à nossa vocação miscigenada.

Aliás, o acalanto tem um lugar excepcional nessa obra, com especial destaque para a função da voz e da musicalidade, tanto em sua perspectiva psicanalítica quanto em sua abordagem antropológica e social. $\mathrm{O}$ autor destaca que "o ritmo estruturado e previsível permite antecipar, sem surpresas, o encadeamento da frase musical" (p. 177); propiciando certa redução do Outro a uma atmosfera benfazeja e asseguradora. Ao mesmo tempo que o conteúdo dessas "cantigas de ninar" descrevem em geral situações terríveis, destinadas a exorcizar pela voz, na transfiguração do horror em beleza, tanto para a mãe quanto para a criança, a dimensão atroz do silêncio e do Nada. Constatação radical, de que não há Outro a quem recorrer. O que me faz rememorar o pedido de meu filho, quando na idade de 6 anos, no momento duro da perda de seu amado avô, me pede para, ao invés de lermos histórias na hora de dormir, cantarmos, dizendo: "Mamãe, é preciso cantar porque quando a gente canta o mal sai pela boca e a felicidade entra pelo ouvido".

Bom, ficaria aqui, no deleite dessa obra, que é coroada ao final com um verdadeiro conto erótico que revela a indiscutível verve literária de seu autor, ao abordar ao seu estilo a vinculação entre o sono e o gozo sexual. Mas é preciso finalizar, ainda que fiquemos assim, com "gosto de quero mais". 


\section{Referências}

Freud, S. (1996). O delírio e os sonhos na "Gradiva" de W. Jensen. In Obras completas (vol. IX). Buenos Aires, AR: Amorrortu. (Trabalho originalmente publicado em 1907).

Lacan, J. (2003). Homenagem a Marguerite Duras pelo arrebatamento de Lol V. Stein, In Outros escritos (pp. 198-205). Rio de Janeiro, RJ: Jorge Zahar. (Trabalho originalmente publicado em 1965).

Citação/Citation: Mello, D. M. (2021, dez.). O Mário que existe em nós. Resenha do livro $A$ erótica do sono. Revista Latinoamericana de Psicopatologia Fundamental, 24(4), 792-796. http://dx.doi.org/10.1590/1415-4714.2021v24n4p792.15

Editora/Editor: Profa. Dra. Marta Regina de Leão D’Agord

Submetido/Submitted: 20.11.2021 / 11.20.2021 Aceito/Accepted: 3.12.2021 / 12.3.2021

Copyright: (C) 2009 Associação Universitária de Pesquisa em Psicopatologia Fundamental/ University Association for Research in Fundamental Psychopathology. Este é um artigo de livre acesso, que permite uso irrestrito, distribuição e reprodução em qualquer meio, desde que o autor e a fonte sejam citados / This is an open-access article, which permits unrestricted use, distribution, and reproduction in any medium, provided the original authors and sources are credited.

\section{Denise Maurano Mello}

Psicanalista; Escritora; Doutora em Filosofia pela Pontifícia Universidade Católica do Rio de Janeiro - PUC-Rio (Rio de Janeiro, RJ, Br) e Université Paris XII (Paris, França); Pós-doutora em Letras pela Pontifícia Universidade Católica do Rio de Janeiro - PUC-Rio (Rio de Janeiro, RJ, Br) e psicanálise pela Université Nice (Nice, França); Professora titular da Universidade Federal do Estado do Rio de Janeiro - Unirio (Rio de Janeiro, RJ, Brasil). Av. Bartolomeu Mitre, 41, cobertura - Leblon 22431-002 Rio de Janeiro, RJ, Br dmaurano@corpofreudiano.com.br https://orcid.org/0000-0003-3498-3773

(cc) BY-NC

This is an open-access article, which permits unrestricted use, distribution, and reproduction in any medium for non-commercial purposes provided the original authors and sources are credited. 